\title{
SOCIO-DEMOGRAPHIC CORRELATES OF JOB SATISFACTION AMONG NURSES AND MIDWIVES IN HEALTH FACILITIES IN THE BOLE DISTRICT OF THE SAVANNAH REGION, GHANA
}

\author{
Datuah $^{1}$, J. N., *Aninanya 2 , G. A., Habib ${ }^{3}$, I. \& Aryee ${ }^{4}$, P. A. \\ ${ }^{1}$ Bole Nursing and Midwifery Training College, Post Office Box 11, Bole, Savannah Region \\ ${ }^{2}$ Department of Health Services Policy, Planning, Management and Economics, School of Public Health, University for Development Studies \\ ${ }^{3}$ Department of Global and International Health, School of Public Health, University for Development Studies \\ ${ }^{4}$ Department of Global and International Health, School of Allied Health Sciences, University for Development Studies \\ *Corresponding author's, Email address: gapiung@gmail.com/ganinanya@uds.edu.gh.
}

\begin{abstract}
In the Ghanaian health system, low job satisfaction has been shown to affect service delivery. It is indicated that poor remuneration, non-conducive working environments and poorly resourced healthcare facilities influence job satisfaction and affect quality healthcare delivery. In this study, the relationship between sociodemographic variables and job satisfaction were examined. An analytical cross-sectional design and a multistage sampling technique were employed and the Mueller/McCloskey Nurse Job Satisfaction Scale was adapted and used to carry out interviews among 156 nurses and midwives in the Bole District of the Savannah Region. Spearman's correlational analysis was done at 95\% confidence level $(p<0.05)$ to establish the association between socio-demographic characteristics and job satisfaction. The study revealed that only few (4.5\%) nurses and midwives had a very high job satisfaction level but a majority (78.7\%) had a modest level of job satisfaction. Also, an association was established between job type by healthcare profession and job satisfaction $(r=0.253, p=0.046<0.05)$. However, there was no relationship between gender $(r=-0.153$, $p=0.872>0.05) ;$ age $(r=0.098, p=0.922>0.05) ;$ marital status $(r=-0.120, p=0.137>0.05)$; level of education $(r=0.055, p=0.576>0.05)$; working experience $(r=0.135, p=0.094)$ and job satisfaction. Job type by healthcare profession was the only socio-demographic variable that predicted job satisfaction. Whilst the midwives were more likely to be dissatisfied, the nurses were more likely to be satisfied. It is recommended that nursing leaders and policy makers should institute motivational packages in consonance with the job types of these health professionals and respecting their rights to be involved in decision making and creating fair promotion opportunities.
\end{abstract}

Keywords: Nurse, Midwife, Job Satisfaction, Socio-demographic Factors, Bole District

\section{Introduction}

Globally, job satisfaction of health professionals is of significant interest to managers of health services, non-governmental organisations and policymakers because it is significantly associated with performance (Bekru, Cherie, \& Anjulo, 2017;

Datuah et al., 2021: UDSIJD Vol 8(2)
Cerasoli, Nicklin, \& Ford, 2014; Lu, Zhao, \& While, 2019; Usman \& Danish, 2010).

A significant and strategic resource in the healthcare industry for improved healthcare delivery is to be found in nurses and midwives due

DOI: https://doi.org.10.47740/604.UDSIJD6i 
to the services they provide which contribute significantly to enhance the quality of life of individuals as well as to sustainable national development (Dignani \& Toccaceli, 2013). In lowand middle-income countries, this category of health professionals provide $87 \%$ of maternal and neonatal health services, and are able to reduce about two-thirds of maternal and neonatal deaths (WHO, 2014). Nevertheless, maternal deaths are still high, especially in developing countries where about $99 \%$ of all maternal deaths have been recorded with more than half of such deaths occurring in Sub-Saharan Africa (WHO, UNICEF, UNFPA, 2019).

Currently, Ghana's maternal mortality ratio is 319 deaths per 100,000 live births whereas the neonatal mortality rate is 25 deaths per 1,000 live births (Ghana Statistical Service (GSS), Ghana Health Service (GHS), 2018). All the same, job satisfaction of health workers including nurses and midwives cannot be glossed over if the government wants to drastically reduce maternal and neonatal deaths and contribute to the achievement of Sustainable Development Goal 3 (Choi, Cheung, \& Pang, 2013). Health professionals' efficiency and productivity depend on a variety of determinants, and job satisfaction plays a large role (Bekru et al., 2017; Chaulagain \& Khadka, 2012; Uçuk \& Güler, 2016). Job satisfaction is described as either a positive or negative attitude or feeling of an employee towards his/her job based on how he or she perceives the work and work environment (Moinul et al., 2013). If employees exhibit positive feelings and attitudes in their work, it means they are by and large satisfied with their work whereas if they show negative attitudes, it implies they are dissatisfied with their work (Lu et al., 2019; Uçuk \& Güler, 2016). Thus, job satisfaction has a significant impact on employees' physical, emotional, psychological dimensions as well as a major attribute of employees' job related behaviours (Willcox et al., 2015). Additionally, job satisfaction may determine employees' productivity, absenteeism, turnover intentions and strike actions (Uçuk \& Güler, 2016).
Understanding the job satisfaction of employees is an essential organisational goal for both the private and public sector institutions especially for organisations that are obsessed with quality outcomes, are client-centred, want to achieve efficiency in their outcome and ultimately want to stay competitive in their area of practice (AlSawai1\& Al-Shishtawy, 2015).

Generally, empirical evidence on job satisfaction among healthcare professionals shows that they expressed low to moderate satisfaction with their job (Aduo-Adjei et al., 2016; Elsherbeny \& Elmasry, 2018). Some studies have shown that, an opportunity for professional development, having clear and specific job duties, recognition, appreciation, and good staff relationships promote job satisfaction. In contrast, low salaries, insufficient incentives and poor leadership style, job stress and inadequate performance appraisal systems are frequently perceived to be responsible for their low satisfaction (Mekuria, Mengistu, \& Bali, 2015; Kahiga, 2018).

Even though low job satisfaction amongst employees is undesirable in every profession, it is significantly dangerous if it occurs among nurses and midwives in the healthcare system. Thus, job satisfaction is paramount and inclusively relevant to all the dimensions and well-being of nurses and midwives, and consequently affects their job productivity, performance, efficiency, absenteeism and turnover rates (Thuita \& Oiye, 2018). Complex work schedules, lack of motivation, inadequate staffing coupled with workload and stress are yet among factors that may result in financial and physiological discomfort for healthcare professionals (Willis-Shattuck et al., 2008). The primary goals of healthcare professionals are to restore health, alleviate pain and promote health. None of these goals can be achieved if there is low job satisfaction among them. Unless nurses and midwives maintain a positive attitude towards their profession just for the sake of their clients they will inevitably fail in their professional career (Chaulagain \& Khadka, 2012).

DOI: https://doi.org.10.47740/604.UDSIJD6i 
In Ghana, earlier evidence suggests that nurses and midwives experience burnout (Odonkor, 2020) and they are not quite satisfied with their jobs (Aquah, 2018; Kotei, 2014). Their job satisfaction is mainly influenced by work-related factors, lack of appreciation for work done, lack of recognition, low pay, career advancement and poor working conditions (Bonenberger et al., 2014). Additionally, some nurses and midwives do not accept postings to the rural areas especially the five regions in Northern Ghana due to the fear of higher workload with no incentives, problems with professional upgrading, prolonged rural stay as well as the feeling of losing moonlight income (locum) which they would have been enjoying if working in the urban areas like Kumasi and Accra (Snow et al., 2011). Furthermore, shortages of nurses in the Ghanaian health system especially in the northern part of Ghana are mostly due to the lower remuneration on their job (McCranie et al., 2011).

Also, evidence on the association between demographic factors and nurses' and midwives' job satisfaction are mixed (Reid et al., 2013a; Uçuk \& Güler, 2016). A review of published works in some developing countries revealed that sociodemographic characteristics of nurses' and midwives' affect job satisfaction in a number of ways (Aklilu et al., 2020; Reid et al., 2013a). Oyibo (2015) reported that age was significantly correlated with job satisfaction of nurses, as elderly nurses and midwives were more satisfied with their jobs than their younger counterparts. Also, those who were married were more satisfied with their jobs than those who were not married (Oyibo, 2015). It appears those married were getting necessary support from their spouses and that gave them the psychological satisfaction to perform their roles at the work place. However, other studies have also suggested that there is no association between demographic factors and job satisfaction of healthcare professionals (Indumathy \& Ravichandran, 2016; Khavayet et al., 2017; Rahnavard et al., 2018).

In Ghana, although there are previous studies on determinants of job satisfaction of healthcare

Datuah et al., 2021: UDSIJD Vol 8(2) professionals, these studies were qualitative in nature and did not assess the correlation between demographic factors and job satisfaction of nurses and midwives (Agyepong et al., 2004; Prytherch et al., 2012, 2013). Also, there is no current evidence on the levels of job satisfaction among nurses and midwives in Ghana, including the Bole District. Therefore, the ultimate objective of this study was to assess the level of job satisfaction and its relationship with socio-demographic variables among nurses and midwives using the Bole District as a proxy. The result of the study will enable healthcare managers and policy makers to develop and implement appropriate incentive policies towards improving the undesirable conditions and strengthening the desirable conditions to reinforce quality healthcare outcomes for the populace, including a reduction in maternal and neonatal health outcomes (Aninanya et al., 2016; Bekru et al., 2017).

\section{Methodology \\ Study Site}

This facility-based study was conducted among 155 practising nurses and midwives in the Bole District of the Savannah Region for a period of two weeks (15 ${ }^{\text {th }}$ to $30^{\text {th }}$ June, 2019). The nurses and midwives in the district frequently grumbled over poor leadership style and inequitable promotion policies. Anecdotal evidence suggests that health workers working in health facilities in the area were not permitted to up-grade themselves in programmes that they preferred but rather were made to pursue programmes that management would recommend. In this regard, any health professional who did not adhere to the directive was punished (Nursing \& Midwifery Council, 2017). Due to these issues, nurses and midwives in the Bole District were purported not to be satisfied with their jobs. Thus, in 2016, to show management their displeasure, they embarked on a strike action for three weeks which affected their productivity (Nursing \& Midwifery Council, 2017).

The Bole District has a population of 61,593 , made of $51.4 \%$ males and $49.6 \%$ females (Ghana

DOI: https://doi.org.10.47740/604.UDSIJD6i 
Statistical Service, 2014). The health infrastructure in the district includes a district hospital, seven health centres, eighteen Community-based Health Planning and Services (CHPS) compounds and twenty-one demarcated CHPS zones. Provision of health services is done by two hundred and thirtyseven health professionals. They include 175 nurses and 34 midwives (Ghana Health Service, 2018).

\section{Study design}

An analytical cross-sectional design with multistage sampling technique was employed to measure the level of job satisfaction and to subsequently determine the relationship between demographic factors and job satisfaction of the nurses and midwives. This design was able to establish the relationship between health-related state and other variables of interest as they exist in a defined population at a single point in time (Kesmodel, 2018).

\section{Sampling size and Technique}

The study population comprised nurses and midwives in health facilities within the Bole district. At the time of the study, there were 175 nurses and 34 midwives in the district. Based on the Yamane's sample size formulae, one hundred and twenty-two (122) nurses were systematically selected whilst all the 34 midwives in the district were included in the study. Yamane (1973) depicts the formula as $\mathrm{n}=\mathrm{N} /\left(1+\mathrm{Ne}^{2}\right)$. Where $\mathrm{n}=$ Sample size required, $\mathrm{e}=$ Margin of error $\mathrm{N}=$ Population size.

A multistage sampling technique was employed in this study. The study sites (the district hospital, 7 health centres and the 18 functional CHPS compounds) were put into eight strata. The basis for this stratification was geographical location and sub-district categorization. Each of the health centres as well the Bole District Hospital together with their functional CHPS compounds were considered as a stratum. Each stratum had its own register which made it easier to sample the nurses. This procedure was followed with a simple random sampling method. That is, names of all the nurses in each stratum register were written on small

Datuah et al., 2021: UDSIJD Vol 8(2) pieces of paper which were then folded and put in a container and the lottery method used in the selection of each participant.

\section{Data Collection Tools and Procedures}

The Mueller/McCloskey Nurse Job Satisfaction Scale helped to examine job satisfaction of nurses and midwives because it is a validated tool for the assessment of job satisfaction of workers (Clinton et al., 2015). However, consideration was given to include other independent questions that could be used to examine job satisfaction factors among nurses since not much is known about the determinants of nurses' job satisfaction (Mueller \& McCloskey, 1990). Thus, fifteen (15) questions were added to the original tool, which had 29 questions, making a total of 44 questions. The tool measured three satisfaction scales, namely intrinsic factors, extrinsic factors and overall satisfaction as well as socio-demographic factors. The demographic factors were age, marital status, gender, educational qualification, working experience (years of service) and job type (nurses, mid-wives and nurse assistants) of respondents. Three trained research assistants assisted in conducting the interviews. Study participants indicated their level of job satisfaction on a threepoint Likert scale (very satisfied, moderately satisfied and very dissatisfied). Before the actual interviews, a pre-test was done at the Sawla PolyClinic among 20 nurses and midwives to ensure the appropriateness of the questions.

\section{Data Analysis}

The completed questionnaires were assessed for inconsistencies and overstated patterns of response. One questionnaire was not properly filled and was therefore excluded from the analysis. Both descriptive and inferential analyses were performed on socio-demographic variables and overall job satisfaction using the Statistical Package for Social Science (SPSS) software version 22.0. Spearman's correlation analysis was performed to establish the relationship between respondents' sociodemographic variables and nurses' and midwives' job satisfaction. Spearman's correlation was conducted between the overall job satisfaction level

DOI: https://doi.org.10.47740/604.UDSIJD6i 
of respondents and the following sociodemographic characteristics; gender, age, marital status, educational level, job type and working experience. Significance level of the inferential analysis was set at $\mathrm{p}>0.05$.

\section{Ethics}

The Navrongo Health Research Centre Institutional Review Board granted authors ethical approval (NHRC IRB 346) before the commencement of the study. Furthermore, administrative approvals were obtained from the then Northern Regional Health Directorate, the Bole District Health Directorate and from management of health centres before participants were recruited to participate in the study. Also, informed consent was sought from all participants before interviews were carried out. Main issues discussed with the nurses and midwives during the consent process were the rationale of the study, procedures involved in the study, voluntarism, risks and benefits and who to contact in case of any additional issues after the interviews.

\section{Results}

\section{Demographic Characteristics of Study Participants}

Of the 154 study participants, majority (71.6\%) were female. More than half $(56.7 \%)$ of them were between 26-35 years. Only one nurse of the nurse assistant category was within 46-55 years while three midwives fell within the age ranges of 21-25 years. On the marital status of respondents, more than half $(62.6 \%)$ of them were married. For the highest level of academic and professional qualification attained, majority $(56.8 \%)$ had a certificate in either enrolled nursing or community health nursing. Additionally, $41.9 \%$ of them had 46 years of working experience, $32.9 \%$ had $1-3$ years while only $2 \%$ had more than 13 years of working experience. Concerning job type by health profession, 34 were midwives, 38 nurses and 83 were nurse assistants (Table 1.0).

Table 1.0: Socio-demographic characteristics of respondents

\begin{tabular}{|c|c|c|c|c|}
\hline Variables & $\begin{array}{l}\text { Total } \\
(n=155)\end{array}$ & $\begin{array}{l}\text { Midwives } \\
(\mathrm{n}=34)\end{array}$ & $\begin{array}{l}\text { Nurses } \\
(\mathrm{n}=38)\end{array}$ & $\begin{array}{l}\text { Nurse } \\
\text { Assistants } \\
(\mathrm{n}=83)\end{array}$ \\
\hline Gender: no. (\%) & 155 & & & \\
\hline Male & $44(28.4)$ & $0(0.0)$ & $16(42.1)$ & $28(33.7)$ \\
\hline Female & $111(71.6)$ & $34(100.0)$ & $22(57.9)$ & $55(66.3)$ \\
\hline Age: no. (\%) & 155 & & & \\
\hline 21-25years & $11(7.1)$ & $3(8.8)$ & $3(7.9)$ & $5(6.0)$ \\
\hline 26-35years & $88(56.7)$ & $12(35.3)$ & $19(50.0)$ & $57(68.7)$ \\
\hline 36-45years & $51(33)$ & $17(50.0)$ & $14(36.8)$ & $20(24.1)$ \\
\hline 46-55years & $5(3.2)$ & $2(5.9)$ & $2(5.3)$ & $1(1.2)$ \\
\hline Marital status: no. (\%) & 155 & & & \\
\hline Single & $56(36.2)$ & $10(29.5)$ & $11(28.9)$ & $35(42.2)$ \\
\hline Married & $97(62.6)$ & $22(64.7)$ & $27(71.1)$ & $48(57.8)$ \\
\hline Divorce & $1(0.6)$ & $1(2.9)$ & $0(0.0)$ & $0(0.0)$ \\
\hline Co-habitation & $1(0.6)$ & $1(2.9)$ & $0(0.0)$ & $0(0.0)$ \\
\hline Level of education: no. (\%) & 155 & & & \\
\hline Certificate & $88(56.8)$ & $8(23.5)$ & $13(34.2)$ & $67(80.7)$ \\
\hline Diploma & $50(32.3)$ & $22(64.8)$ & $16(42.1)$ & $12(14.5)$ \\
\hline First degree & $15(9.7)$ & $3(8.8)$ & $9(23.7)$ & $3(3.6)$ \\
\hline Masters & $29(1.2)$ & $1(2.9)$ & $0(0.0)$ & $1(1.2)$ \\
\hline
\end{tabular}

Datuah et al., 2021: UDSIJD Vol 8(2)

DOI: https://doi.org.10.47740/604.UDSIJD6i 


\begin{tabular}{lllll}
\hline Working experience: no. $(\%)$ & 155 & & & \\
Less than 1 year & $14(9.0)$ & $2(5.9)$ & $5(13.2)$ & $7(8.4)$ \\
1-3years & $51(32.9)$ & $16(47.1)$ & $11(28.9)$ & $24(28.9)$ \\
4-6years & $65(41.9)$ & $9(26.5)$ & $13(34.2)$ & $43(51.8)$ \\
7-9years & $18(11.6)$ & $3(8.8)$ & $7(18.4)$ & $8(9.6)$ \\
10-12years & $4(2.6)$ & $3(8.8)$ & $1(2.6)$ & $0(0.0)$ \\
13+years & $3(2)$ & $1(2.9)$ & $1(2.6)$ & $1(1.2)$ \\
\hline
\end{tabular}

Source: Field Survey, (2019)

\section{Level of job satisfaction by Job Type}

One hundred and twenty two (78.7\%) of the study participants were moderately satisfied with their jobs. In particular, about $90 \%$ of the nurses were moderately satisfied with their jobs. This was followed by nurse assistants $(79.5 \%)$ and midwives $(67.7 \%)$. However, only seven $(4.5 \%)$ of the study participants indicated high satisfaction with their job. Nurses $(7.9 \%)$ had a very high job satisfaction level as compared to their counterparts (Table 2.0). Nonetheless, $16.8 \%$ of the respondents were very dissatisfied with their jobs. More midwives (29.4\%) were very dissatisfied with their jobs, followed by nurse assistants (16.9\%) and nurses (5.3\%) (Table 2.0).

Table 2.0: Level of job satisfaction by Job Types of Health Profession

\begin{tabular}{lcccc}
\hline Variables & $\begin{array}{l}\text { All } \\
(\mathbf{n = 1 5 5})\end{array}$ & $\begin{array}{l}\text { Midwives } \\
(\mathbf{n = 3 4 )}\end{array}$ & $\begin{array}{l}\text { Nurses } \\
(\mathbf{n = 3 8})\end{array}$ & $\begin{array}{l}\text { Nurse } \\
\text { Assistants } \\
(\mathbf{n}=\mathbf{8 3})\end{array}$ \\
\hline $\begin{array}{l}\text { Overall job satisfaction: } \mathbf{n}(\%) \\
\text { Very Satisfied }\end{array}$ & $7(4.5)$ & $1(2.9)$ & $3(7.9)$ & $3(3.6)$ \\
$\begin{array}{l}\text { Moderately Satisfied } \\
\text { Very Dissatisfied }\end{array}$ & $122(78.7)$ & $23(67.7)$ & $33(86.8)$ & $66(79.5)$ \\
\hline
\end{tabular}

Source: Field Survey, (2019)

Relationship between Socio-Demographic Factors and Nurses' and Midwives' Job Satisfaction

The results revealed a negative correlation between gender and job satisfaction which was however not statistically significant $(\mathrm{r}=-0.153, \mathrm{p}=0.872>0.05)$. The study also found a statistically weak positive relationship between age and job satisfaction $(\mathrm{r}=0.098, \mathrm{p}=0.922>0.05)$ and between marital status and job satisfaction $(\mathrm{r}=-0.120, \mathrm{p}=0.137>0.05)$ (Table 3.0).

A weak positive relationship also existed between educational level and job satisfaction $(r=0.055, p=0.576$ > 0.05 ) which is not statistically significant. Again, working experience had a weak positive relationship with job satisfaction $(\mathrm{r}=0.135, \mathrm{p}=0.094>0.05)$. However, the relationship between job type and job satisfaction was positive $(r=0.253, p=0.046<0.05)$, and statistically significant (Table 3.0). 
Table 3.0: Relationship between demographic variables and overall job satisfaction

\begin{tabular}{|c|c|c|c|c|c|c|c|c|}
\hline & & $\begin{array}{l}\text { Overall job } \\
\text { satisfaction }\end{array}$ & Gender & Age & $\begin{array}{l}\text { Marital } \\
\text { status }\end{array}$ & $\begin{array}{l}\text { Level of } \\
\text { education }\end{array}$ & Job type & $\begin{array}{l}\text { Working } \\
\text { experience }\end{array}$ \\
\hline \multirow{2}{*}{$\begin{array}{l}\text { Overall job } \\
\text { satisfaction }\end{array}$} & Corr. Coeff & 1 & & & & & & \\
\hline & Sig. & & & & & & & \\
\hline \multirow[t]{2}{*}{ Gender } & Corr. Coeff & -0.153 & 1 & & & & & \\
\hline & Sig. & 0.872 & . & & & & & \\
\hline \multirow[t]{2}{*}{ Age } & Corr. Coeff & 0.098 & -0.128 & 1 & & & & \\
\hline & Sig. & 0.922 & 0.112 & . & & & & \\
\hline \multirow{2}{*}{$\begin{array}{l}\text { Marital } \\
\text { status }\end{array}$} & Corr. Coeff & -0.120 & -0.130 & $0.224 * *$ & 1 & & & \\
\hline & Sig. & 0.137 & 0.107 & 0.005 & & & & \\
\hline \multirow[t]{2}{*}{$\begin{array}{l}\text { Level of } \\
\text { education }\end{array}$} & Corr. Coeff & 0.055 & $\begin{array}{l}0.213^{*} \\
*\end{array}$ & $0.198^{*}$ & 0.062 & 1 & & \\
\hline & Sig. & 0.576 & 0.008 & 0.013 & 0.441 & . & & \\
\hline \multirow[t]{2}{*}{ Job type } & Corr. Coeff & $0.253^{* *}$ & $\begin{array}{l}0.227 * \\
*\end{array}$ & $-0.210^{* *}$ & -0.129 & $-0.473 * *$ & 1 & \\
\hline & Sig. & 0.046 & 0.004 & 0.009 & 0.110 & 0.000 & & \\
\hline \multirow{2}{*}{$\begin{array}{l}\text { Working } \\
\text { experience }\end{array}$} & Corr. Coeff & 0.135 & -0.067 & $0.236^{* *}$ & $0.207 * *$ & 0.005 & 0.043 & 1 \\
\hline & Sig. & 0.094 & 0.411 & 0.003 & 0.01 & 0.955 & 0.594 & \\
\hline
\end{tabular}

Source: Field Survey, (2019)

Corr. Coeff=Correlation Coefficient. *significant at the 0.05 level (2-tailed). ** significant at the 0.01 level (2tailed)

\section{Discussion}

The study sought to determine the level of job satisfaction among nurses and midwives and the relationship between socio-demographic factors and job satisfaction. Majority of the nurses and midwives in health facilities in the Bole District recorded a moderate level of job satisfaction, which was more likely among nurses than nurse assistants and midwives. This is consistent with the findings of Kadar et al., (2016) who revealed moderate satisfaction of nurses with their jobs in health facilities in Turkey, but this was in private hospitals. Similarly, another study in Benin also reported that nurses and midwives were moderately satisfied with their jobs (Ayivi-Guedehoussou, 2017).

Datuah et al., 2021: UDSIJD Vol 8(2)
However, in contrast, Kotei (2014) found low level job satisfaction among nurses in the Kintampo Municipal Hospital. Also, in Trinidad and Tobago, low job satisfaction was reported among nurses and midwives (Mitchell \& Esnard, 2011). Nevertheless, Ahmed et al., (2011) reported higher satisfaction among healthcare professionals with intrinsic factors in North America which contradicts the current finding. Any level of job satisfaction among nurses and midwives has direct and indirect consequences on performance and outcome of service delivery (Nyirenda \& Mukwato, 2016).

A preponderant moderate job satisfaction among the nurses and midwives in this study may imply that respondents are generally satisfied with their nursing duties and responsibilities. This could also mean that respondents appreciate to some extent the

DOI: https://doi.org.10.47740/604.UDSIJD6i 
policies of the Ghana Health Service about their duties and responsibilities. It is also possible that managers of the health facilities in the Bole District may be ineffective and inefficient in ensuring favorable working conditions for respondents, which could also be a reason for respondents' moderate satisfaction with their jobs.

Among the health professionals in the study, the nurses were also more likely to be highly satisfied with their jobs compared to the nurse assistants and midwives, whilst the midwives were more likely to be dissatisfied. However, very few respondents were highly satisfied with their jobs and this is consistent with a study by Kotei (2014) who found low level job satisfaction among nurses in the University of Ghana Hospital. The study population of this quantitative survey was mainly nurses but the current study involved both nurses and midwives. Also, in Trinidad and Tobago, low job satisfaction was reported among nurses (Mitchell \& Esnard, 2011). In this latter study, only eighty-three nurses in four public health facilities participated but the current study involved 155 nurses and midwives. The current finding is also similar to studies conducted in other sites in Ghana and Tanzania that revealed that maternal and neonatal healthcare providers had moderate satisfaction with their jobs (Prytherch et al., 2012; Prytherch et al., 2013). These previous qualitative studies were done among purposively selected maternal and neonatal healthcare providers but the current quantitative study was done among randomly selected nurses and midwives.

In respect of sociodemographic variables, the study showed that marital status had a weak negative association with job satisfaction but was statistically not significant. This finding is in consonance with the study of Panisoara \& Serban (2013), who established a weak association between marital status and employees' job satisfaction in Romania. Another study in India (Dar \& Najar, 2018) equally reported a weak correlation between marital status and healthcare professionals' job satisfaction. However, Ugwa (2016) and Demİrtaş (2015), found no association

Datuah et al., 2021: UDSIJD Vol 8(2) between marital status and job satisfaction. In yet another study among administrative staff in Midwestern University of Ohio state, marital status was not significantly related to job satisfaction (Issah, 2013). A weak positive or no relationship between marital status and job satisfaction means that being in a marital relationship does not influence the individual's job satisfaction, which may be attributed to modernisation in the $21^{\text {st }}$ century where men and women, irrespective of their marital status have to compete for career development and with shared family and societal responsibilities.

The study also showed a weak positive but statistically not significant connection between age and job satisfaction. However, AyiviGuedehoussou, (2017) revealed no association between age and job satisfaction among study participants in Benin. Another study in Turkey reported by Demİrtaş, (2015) among employees of a firm but not nurses and midwives revealed that there was no association between job satisfaction and age of employees. There is likely a confounding factor accounting for the weak association between age and job satisfaction in this study since a lot more of the study participants were young, and earning a salary at a younger age should be motivating to promote job satisfaction. It could also imply that younger respondents like their older counterparts, probably had financial and other obligations that weighed down their earnings.

On the part of gender, the correlation analysis yielded a weak negative but not significant association with nurses and midwives' job satisfaction. The study by Concialdi (2014), lends credence to the findings of the current study by reporting that there was no relationship between gender and job satisfaction among employees. However, contrasting results to the present study by Zare \& Salar (2016), reported that there was a connection between job satisfaction and workers' gender. Also, findings by Saner \& Eyupoglu (2015) revealed high satisfaction among female employees than males in North Cyprus. Most of these studies were mainly on diverse employees

DOI: https://doi.org.10.47740/604.UDSIJD6i 
because related findings on gender and nurses' and midwives' job satisfaction are sparse. Nevertheless, previous works suggest that nursing is fostering, feminine, and a soft profession recommended for females (Frimpong, 2016). It also appears that all category of females in the African context take-up the caring roles for sick family members in our homes. These feminine gender roles conform to the nursing activities and may have accounted for the current study revealing majority of respondents as females.

With regards to respondents' educational level, a weak positive relationship with job satisfaction was established. This finding is in agreement with the results of Kavanaugh, Duffy \& Lilly (2006), who found educational qualification to have less impact on job satisfaction among health professionals. The finding also supports Oluwatobi \& Ajie (2015) who reported no association between the educational qualification of nurses and their job satisfaction and commitment in the Ogun state of Nigeria. However, Mekuria \& Mengistu (2015) reported level of education to be significantly associated with job satisfaction among 166 randomly selected healthcare workers in public hospitals in West Shoa Zone, Oromia Region, Ethiopia. Furthermore, the findings of Wambugu, Ombui, and Campus (2013) reported educational qualification among healthcare professionals in Kenya as the highest motivating factor. This is not surprising because the authors specifically examined job motivation but not job satisfaction.

The weak association between educational level and job satisfaction might be attributed to the lower academic status of some respondents especially among the nurse assistants. However, in examining the results, it can be observed that the nurses who were more likely to be moderately satisfied were also more likely to possess degrees for their profession as compared to the midwives and nurse assistants (Table 1). In ideal conditions, people with higher educational qualifications occupy higher offices, enjoy better privileges and opportunities as well as receive better salaries. Abdullah \& Maqbali (2015) found that healthcare professionals with a

Datuah et al., 2021: UDSIJD Vol 8(2) first degree had higher job satisfaction than their colleagues who were employed with Diploma certificates. Similarly, in Ghana, senior nursing officers were observed to have higher job satisfaction than nurse assistants (Kotei, 2014b). This high job satisfaction means that education is considered a critical factor in human resource recruitment and a determinant of job satisfaction. Technological advancement in the management of various disease conditions and the epidemiological transition of disease burden has made education crucial in the nursing profession as competent, knowledgeable and technological inclined nurses and midwives are needed for the implementation of contemporary healthcare interventions. It is a fact that nurses who take the pain to advance in their professional career will expect to be rewarded by promotion, upgrading and change of job description (Mekuria \& Mengistu, 2015).

The correlation analysis produced a weak positive but statistically significant relationship between job type and job satisfaction. This means that job type of health professionals is a predictor of job satisfaction among the respondents. The finding aligns with the conclusions of Reid, Hurst \& Anderson (2013), who reported job satisfaction among healthcare professionals to be significantly associated with their specialty areas. One major characteristic of nursing as a profession is the ability to work in a diverse type of environment and many different roles because it is a field that is continually changing. The job type, educational status, location, hours of work, and experience also impact on nurses' salary and job satisfaction which is one of the implications of this correlation result. The job roles and work settings for each of the nursing categories; community health nurse, midwife, general nurse or an auxiliary nurse/nurse assistant varies significantly from each other though they all work toward achieving the same goal. For example, a nurse-midwife is one that has specialized training in obstetrics. This category of health staff renders maternal and child services to clients (Nursing and Midwifery Council, 2018). A registered general nurse does bedside nursing,

DOI: https://doi.org.10.47740/604.UDSIJD6i 
through direct or indirect collaboration with the other health team members to help patients. In comparison, a community health nurse's ultimate goal is to ensure healthy living among the citizenry through preventive interventions (NMC, 2018). It is a fact that each of these categories will attach significance, value and superiority to its job type thereby demanding higher salary, recognition, respect and appreciation in return.

Furthermore, working experience is yet one of the demographic variables that produced an insignificant, weak positive relationship with job satisfaction. Kahiga (2018) as well as Abdullah \& Maqbali (2015), reported that health workers who are between $40-45$ years and have 5 years working experience are more satisfied with their jobs especially with the intrinsic factors than their colleagues health workers who have $<2$ years working experience, which confirms the finding in the current study as a majority were observed to have less than three years working experience. The present study is also a reflection of that by Tiwari (2011), who reported that years of working experience among healthcare professionals is not associated with their job satisfaction. In the same vein, working experience was shown not to be related to nurses' job satisfaction in public hospitals in Saudi Arabia (Alshmemri, 2014; Indumathy \& Ravichandran, 2016). It is most likely that these studies were done among relatively inexperienced professionals who may have been working for fewer years. With job satisfaction, the more experienced an employee is in his/her field of practice, the less stressful he/she becomes in performing his/her duties and the better the outcomes. Thus, junior nurses and midwives, who have been working for shorter periods need mentoring and coaching from the experienced ones for better healthcare delivery.

Sekhametsi (2014) asserted that demographic variables have less significant relationships with nurses' turnover rate when compared with nonfinancial factors, accommodation for staff, and lack of proper infrastructure to operate remote clinics. Nevertheless, there is a need to implement

Datuah et al., 2021: UDSIJD Vol 8(2) strategies based on such socio-demographics as education and job type to improve job satisfaction for these health professionals to enable them contribute to the reduction of maternal morbidities and mortality.

\section{Study Limitations}

The study has filled an evidence gap on association between socio-demographic factors and job satisfaction among nurses and midwives in the Bole District and for that matter in Ghana. Nonetheless, the study yielded only numerical data without unveiling respondents' feelings and perceptions about their situations. The authors therefore suggest that future qualitative studies be conducted to explore the relationship between demographic factors and job satisfaction of nurses and midwives. Also, the scope of the study was limited to only nurses and midwives in health facilities in the Bole District. The authors suggest that future studies should concentrate on other nursing populations and should assess other determinants of job satisfaction.

\section{Conclusions}

The study revealed that only few nurses and midwives had a very high job satisfaction level. Nonetheless, a majority of nurses and midwives had a modest level of job satisfaction. This modest level of job satisfaction may have long-term effects on healthcare delivery in Ghana by discouraging interested individuals from pursuing nursing and midwifery as careers. Also, the study established weak associations between gender, age, marital status, educational level, work experience and overall job satisfaction, which were all not significant. However, job type and nurses' and midwives' job satisfaction were statistically significant. Thus, job type appears to be the major determinant of job satisfaction among nurses and midwives.

This implies that job type by healthcare profession should be considered significant in the context of healthcare delivery. For universal healthcare coverage and quality healthcare delivery, nursing leaders and policy makers should institute

DOI: https://doi.org.10.47740/604.UDSIJD6i 
motivational packages that include respecting the rights of the different categories of nurses and midwives, their involvement in decision making and creating fair promotion opportunities. Motivational packages should also include end of year reward systems and provision of adequate resources for their work.

\section{Competing Interest}

Authors have no competing interest

\section{Declarations}

\section{Author contributions}

JND designed and implemented the study as part of his Master of Philosophy thesis and drafted the article. GAA rigorously supervised Master of Philosophy thesis, contributed in drafting the article and substantially revised the article. HI also contributed to data analysis and reviewed the article. PAA contributed significantly to data interpretation and substantially revised the article.

\section{Acknowledgment}

Authors are grateful to all study participants and the Bole District Health Directorate for the maximum support given to them during the data collection activities.

\section{References}

Acquaye, A. (2007). Job satisfaction, occupational stress and mental health among nurses in the Greater Accra Metropolis. Retrieved from: https://doi.org/10.1007/s00431-012-1836 on $15^{\text {th }}$ March 2020.

Aduo-Adjei, K., Emmanuel, O. \& Forster, O. M. (2016). The Impact of Motivation on the Work Performance of Health Workers (Korle Bu Teaching Hospital): Evidence from Ghana. Hospital Practices and Research, 1(2), 45-50.

Agyepong, I. A., Anafi, P., Asiamah, E., Ansah, E. K., Ashon, D. A. \& Narh-Dometey, C. (2004). Health worker (internal customer) satisfaction and motivation in the public sector in Ghana.

Datuah et al., 2021: UDSIJD Vol 8(2)
International Journal of Health Planning and Management, 19(4), 319-336.

Ahmed, M. M., Uk, F. \& Al-githmi, F. I. (2011). Factors Influencing Job satisfaction of employees. Bahrain Med Bull, 33(2), 1-8.

Al Maqbali, M. A. (2015). Factors that influence nurses' job satisfaction: a literature review. Nursing management (Harrow, London, England: 1994), 22(2), 30-37.

Aninanya, G. A., Howard, N., Williams, J. E., Apam, B., Prytherch, H., Loukanova, S., Kamara, E. K. \& Otupiri, E. (2016). Can performance-based incentives improve motivation of nurses and midwives in primary facilities in northern Ghana? A quasiexperimental study. Global Health Action, 9(1), 1-10.

Ayivi-Guedehoussou, N. (2017). The Determinants of Job Satisfaction among Nurses, Midwives, and Auxiliary Nurses in Health Clinics: The Case of Bénin, West Africa. Retreived from: https://doi.org/10.7249/rgsd373 on June, 2019.

Bekru, E. T., Cherie, A. \& Anjulo, A. A. (2017). Job satisfaction and determinant factors among midwives working at health facilities in Addis Ababa city, Ethiopia. Plos one Journal, 07, 1-16.

Bonenberger, M., Aikins, M., Akweongo, P. \& Wyss, K. (2014). The effects of health worker motivation and job satisfaction on turnover intention in Ghana: A cross-sectional study. Human Resources for Health, 12, 43.

Cerasoli, C. P., Nicklin, J. M. \& Ford, M. T. (2014). Intrinsic motivation and extrinsic incentives jointly predict performance: A 40-year metaanalysis. Psychological Bulletin, 140(4).

Chaulagain, N. \& Khadka, D. K. (2012). Factors Influencing Job Satisfaction among Healthcare Professionals at Tilganga Eye Centre, Kathmandu, Nepal. International

DOI: https://doi.org.10.47740/604.UDSIJD6i 
Journal of Scientific \& Technology Research, 1(11), 32-36.

Choi, S. P.-P., Cheung, K. \& Pang, S. M.-C. (2013). Attributes of nursing work environment as predictors of registered nurses' job satisfaction and intention to leave. Journal of Nursing Management, 21(3), 429-439.

Clinton, M., Dumit, N. Y. \& El-Jardali, F. (2015). Rasch Measurement Analysis of a 25-Item Version of the Mueller/McCloskey Nurse Job Satisfaction Scale in a Sample of Nurses in Lebanon and Qatar. SAGE Open, 5(2).

Concialdi, C. (2014). The role of gender, age , occupational position and job performance on employees 'job satisfaction. A Thesis Paper. Retrieved from: https://www.semanticscholar.org/paper/Therole-of-gende on january, 2020.

Aquah, C. (2018). Assessment of factors influencing job satisfaction among nurses at the Greater Accra Regional Hospital. Thesis Paper : Retrievd from: http://ugspace.ug.edu.gh/ on $14^{\text {th }}$ June, 2019 ..

Nursing \& Midwifery Council, Ghana (2017). Induction Ceremony for newly qualified nurses and midwives. Induction Ceremony for Newly Quaified Nurses and Midwives Retrieved from: httpp//ghananews/health.com on 20th July, 2019.

Dar, W.A. \& Najar, I.A. (2017). Job satisfaction of plus two male lecturers of District Budgam with respect to their marital status. International Journal of Multidisciplinary Education and Research, 2, 60-63.

Demİtaş, Z. (2015). The Relationship Between Job Satisfaction And Organizational Commitment: A Study on Elementary Schools. Thesis Paper. Retrieved From: https://dergipark.org. On $20^{\text {th }}$ June, 2019.

Dignani, L., \& Toccaceli, A. (2013). Nurses and

Datuah et al., 2021: UDSIJD Vol 8(2)
Job Satisfaction. Journal of US-China Public Adminstration, 10(4), 379-387.

Elsherbeny, E., \& El-masry, R. (2018). Job Satisfaction Among Nurses Working In Mansoura University Hospital: Effect Of Socio-Demographic And Work Characteristics. Egyptian Journal of Occupational Medicine, 42(2), 227-240

Ghana Health Service. (2018). Bole District Annual Report.

Ghana Statistical Service. (2014). Bole district Analytical Report. www.statsghana.gov.gh

Ghana Statistical Service (GSS), Ghana Health Service (GHS), (2018). Ghana Maternal Health Survey 2017. In Accra, Ghana: GSS, GHS, and ICF. Retrieved from: https://doi.org/10.1111/j.14697610.2010 .02280 on March $4^{\text {th }}, 2020$

Indumathy, J., \& Ravichandran, M. (2016). A Study on Socio-Demographic Variables and Its Influence on Job Satisfaction among Tertiary Care Hospital Nurses. 5(12), 1416-1419.

Issah, M. (2013). The Relationship Between Perceptions of Fit and Job Satisfaction. Thesis paper: Retreived from: https://etd.ohiolink.edu on 20 ${ }^{\text {th }}$ June, 2019.

Kadar, A., Masum, M., Azad, A. K., Hoque, K. E., Beh, L., Wanke, P., \& Arslan, Ö. (2016). Job satisfaction and intention to quit: an empirical analysis of nurses in Turkey. PeerJ, 4, Retrieved from https://doi.org on 20th June, 2019.

Kahiga, K. W. (2018). Factors influencing the job satisfaction of nurses working in obstetric units in public hospitals in Kenya. Journal of Nursing Education, 8(2).

Kavanaugh, J., Duffy, A., \& Lilly, J. (2006). The relationship between job satisfaction and demographic variables for healthcare professionals. Management Research News, 29(6), 304-325.

DOI: https://doi.org.10.47740/604.UDSIJD6i 
Kesmodel, U. S. (2018). Cross-sectional studies what are they good for? Acta Obstetricia et Gynecologica Scandinavica (97) 4. 38839397, 388-393. Retreived from: https://doi.org/10.1111/aogs.13331

Khavayet, F., Tahery, N., Ahvazi, M. A., \& Ma, T. (2017). A Survey of Job Satisfaction among Midwives Working in Hospitals.Journal of Midwifery and Reproductive Health, 2018(6)1.1186-1192.

Kotei, M. (2014b). Job satisfaction among nurses in Ghanaian hospitals: The case of University of Ghana hospital (UGH). Retrieved from: https://www.academia.edu/9646924/job_satis faction on $20^{\text {th }}$ March, 2019.

Lesley, D. (2016). Men in a female-dominated profession: The lived experiences of Ghanaian male nurses in the United States. Retrieved from: www.semanticscholar.org/ March, 25 ${ }^{\text {th }}, 2019$.

Lu, H., Zhao, Y., \& While, A. (2019). Job satisfaction among hospital nurses: A literature review. In International Journal of Nursing Studies, 94, 21-31.

Mekuria Mengistu, M., Mengistu, M. M., \& Bali, A. G. (2015). Factors Associated to Job Satisfaction Among Healthcare Workers at Public Hospitals of West Shoa Zone, Oromia Regional State, Ethiopia: A Cross Sectional Study. Science Journal of Public Health, 3(2), 161.

Mitchell, J. A., \& Esnard, T. R. (2011). SocioEconomic Factors and Job Satisfaction among Public Health Care Registered Nurses in Trinidad and Tobago. International Journal of Business and Social Research, 4(6), 27-37.

Moinul, M., Murad, I., Zayed, N. M., Zafar, A., \& Mukul, A. (2013). A Study on Job Satisfaction: Focus on Bankers of Bangladesh. European Journal of Business and Management, 5(17), 14-20.

Datuah et al., 2021: UDSIJD Vol 8(2)
Mueller C.W \& McCloskey J C. (1990). Perioperative nursing implications. International Nursing Review 53(3):224-3

Nyirenda, M., \& Mukwato, P. (2016). Job satisfaction and attitudes towards nursing care among nurses working at Mzuzu Central Hospital. PubMed, 28(4). 159-166.

Odonkor, S. T. (2020). Burnout among Healthcare Professionals in Ghana: A Critical Assessment. BioMed Research International. Retfreived from: https://doi.org/10.1155/2020/1614968

Oluwatobi, O., \& Management, I. R. (2015). Job Satisfaction and Organisational Commitment among Library Personnel in Selected Libraries in Ogun State, Nigeria. Information and Knowledge Management. 5(10), 20-30.

Panisoara, G., \& Serban, M. (2013). Marital Status and Work-Life Balance. Procedia - Social and Behavioral Sciences, 78(2008), 21-25.

Prytherch, Helen, Kagoné, M., Aninanya, G. A., Williams, J. E., Kakoko, D. C., Leshabari, M. T., Yé, M., Marx, M., \& Sauerborn, R. (2013). Motivation and incentives of rural maternal and neonatal health care providers: A comparison of qualitative findings from Burkina Faso, Ghana and Tanzania. BMC Health Services Research. Retreived from: https://doi.org/10.1186 on $25^{\text {th }}$ July, 2020.

Prytherch, Helen, Leshabari, M. T., Wiskow, C., Aninanya, G. A., Kakoko, D. C. V., Kagoné, M., Burghardt, J., Kynast-Wolf, G., Marx, M., \& Sauerborn, R. (2012). The challenges of developing an instrument to assess health provider motivation at primary care level in rural Burkina Faso, Ghana and Tanzania. Global Health Action, 5, 1-18.

Rahnavard, F., Sadati, A. K., Hemmati, S., Ebrahimzade, N., Sarikhani, Y., Heydari, T., Lankarani, K. B., Policy, H., Policy, H., Policy, H., \& Policy, H. (2018). Electronic 
Reid, C., Hurst, C., \& Anderson, D. (2013b). Examination of socio-demographics and job satisfaction in Australian registered nurses. Collegian, 20(3), 161-169.

Salar, A. R., Zare, S., Salar, H., \& Salar, E. (2016). The survey of the job satisfaction rate in the nurses working in the training hospitals of Zahedan University of Medical Sciences. International Journal of Medical Research \& Health Sciences, 5. Retreieved from: https://www.ijmrhs.com.

Saner, T., \& Eyupoglu, S. Z. (2015). The Gendermarital Status Job Satisfaction Relationship of Academics ScienceDirect. Retreievd from: //doi.org/10.1016/j.sbspro on $12^{\text {th }}$ June, 2019

Snow, R. C., Asabir, K., Mutumba, M., Koomson, E., Gyan, K., Dzodzomenyo, M., Kruk, M., \& Kwansah, J. (2011). Key factors leading to reduced recruitment and retention of health professionals in remote areas of Ghana: a qualitative study and proposed policy solutions. Human Resources for Health, 9(1), 13.

Thuita, G., \& Oiye, Y. (2018). Compensation , Working Conditions And Employee Satisfaction In Kilifi Export Processing Zones , Kenya. International Journal of Economics, Business and Management Research, 2(2).

Tiwari, V. (2011). $R$ Elationship Between $M$ Otivation and Job S Atisfaction of The White Collar Employees : A Case Study. Thesis paer. Retreived from: https://www.academia.edu/878195 on july, $12^{\text {th }} 2019$.

Uçuk, S., \& Güler, H. (2016). Job Satisfaction Levels in Midwifery. International Journal of Humanities and Social Science Invention,
5(6), 53-60.

Usman, A., \& Danish, R. Q. (2010). Impact of Reward and Recognition on Job Satisfaction and Motivation: An Empirical Study from Pakistan. International Journal of Business and Management 13(8).

Wambugu, S. M., Ombui, K., Campus, N., \& Campus, N. (2013). Effects of Reward Strategies on Employee Performance at Kabete Technical Training Institute, Nairobi , Kenya. Public Policy and Administration Research,3(7), 19-46.

WHO, UNICEF, UNFPA, W. B. G. and the U. N. P. D. (2019). No Trends in maternal mortality: 2000 to 2017: estimates by WHO, UNICEF, UNFPA, World Bank Group and the United Nations Population Division. Report. Retreived from: https://www.who.int/newsroom/fact-sheets/detail/maternal-mortality on $25^{\text {th }}$ July 2020.

WHO. (2014). Fact Sheet : The State Of The World , $S$ Midwifery.Retrieved from: https://www.unfpa.org/sowmy on the $20^{\text {th }}$ July, 2020.

Willcox, M. L., Peersman, W., Daou, P., Diakité, C., Bajunirwe, F., Mubangizi, V., Mahmoud, E. H., Moosa, S., Phaladze, N., Nkomazana, O., Khogali, M., Diallo, D., Maeseneer, J. De, \& Mant, D. (2015). Human resources for primary health care in sub-Saharan Africa: progress or stagnation? Human Resources for Health. Retfreived from: https://doi.org/10.1186/ on $25^{\text {th }}$ July, 2020.

Willis-Shattuck, M., Bidwell, P., Thomas, S. et al.(2008). Motivation and retention of health workers in developing countries: a systematic review. BMC Health Serv Res 8, 247. 